\title{
Molecular Typing and Phylogenetic Analysis of Cutaneous Leishmania from Iraqi Patients
}

\author{
Mohammed J.S. Al-Ghabban', Nagham Y. Al-Bayati², Qasim S. Al-Mayah ${ }^{3}$ \\ ${ }^{1}$ Assist. Pof., ${ }^{2}$ Prof., Department of Biology, College of Education for Pure Sciences, University of Diyala/Iraq, \\ ${ }^{3}$ Assist. Prof., Medical Research Unit, College of Medicine, Al-Nahrain University/Iraq
}

\begin{abstract}
This study aimed for molecular characterization of local isolates of L. tropica and L. major and their relatedness to reference isolated from neighboring countries. Exudates and dermal tissues were collected from the cutaneous lesions of 50 newly diagnosed patients with CL. Leishmania DNA was extracted from lesion exudate and 5.8S rRNA gene was amplified using two sets of specific primers through nested PCR. A total of 12 PCR products were directly sequenced and the resultant sequences were aligned with reference sequences in National Center for Biotechnology Information (NCBI). A phylogenetic tree was constructed for local Leishmania isolates with the reference isolates using Mega 6 software. According to alignment results out of 12 sequences, 9 sequences were belonging to L. major, while 3 sequences were belonging to L. tropica. All local L. major isolates were very close to reference isolate KP773404.1 (an Iranian isolate), while all local L. tropica isolates were very close to reference isolate KY612611.1 (an Iranian isolate) with an identity of $98 \%$. Phylogenetic trees confirmed that closest isolates for local Leishmania (whether $L$. tropica or L. major) was the Iranian isolate. These data indicate that local isolates of L. tropica and L. major are closely related to Iranian isolates.
\end{abstract}

Keywords: Cutaneous leishmaniasis, phylogenetic analysis.

\section{Introduction}

Leishmaniasis, a disease caused by different species of Leishmania, is the third most significant arthropodborne disease for the global burden of diseases ${ }^{[1]}$. Among the three types of the disease (cutaneous, visceral and mucocutaneous), the cutaneous leishmaniasis (CL) is the most common form of the disease which encompasses about three-fourths of the total cases. This disease is one of the few infectious diseases recently rising in incidence globally ${ }^{[2,3]}$.

Molecular characterization of the causative agent of CL may facilitate the determining molecular

\section{Corresponding Author:}

\section{Mohammed J.S. Al-Ghabban}

Assist. Pof., Department of Biology, College of Education for Pure Sciences, University of Diyala/Iraq e-mail: sciencefond2015@gmail com epidemiology and hence can help in introducing effective control programs. Polymerase chain reaction (PCR) brought about the infusion of techniques for identification and genetic characterization of Leishmania ${ }^{[4]}$. Different genes such as 5.8S rRNA and internal transcribed spacer-1 gene have been used successfully for both diagnosis and molecular characterization of $\mathrm{CL}^{[5]}$. Studies concerning phylogenetic analysis and molecular characterization of L. tropica and L. major are scarce in Iraq despite the endemicity of the disease.

Therefore, this study aimed to molecular characterization of local isolates of $L$. tropica and $L$. major and their relatedness to reference isolated from neighboring countries.

\section{Subjects and Method}

The study Population: This study was performed in the dermatology clinic of Baquba Teaching Hospital in Diyala city/Iraq, from November 2018 to the end of August 2019. A total 30 newly diagnosed patients 
with confirmed CL were included The diagnosis of CL was based on clinical signs and detection of Leishman Donovan bodies with direct microscopic examination after staining of lesion exudate with Geimsa stain.

Dermal scraping: A deep disinfecting of the indurated active margin of the lesion with $70 \%$ ethanol was performed. Samples were taken by using disposable sterile surgical blade to make an incision in the border of the lesion. Exudates and dermal tissues from the wall of the slit were scraped and smeared on two glass slides. The touch impression smears were air dried, methanolfixed, stained with Giemsa and finally examined for amastigotes by microscopy.

Leishmania gene amplification: Leishmania DNA was extracted from lesion exudate using a ready commercial kit (Analytikjena/Germany). Nested PCR technique was used for amplification of $18.5 \mathrm{~S}$ rRNA Leishmania gene. The primers of the first round were forward: 5'- CTGTAGGTGAACCTGCAGCAGCTGGATCATT-3' and reverse: 5'-GCGGGTAGTCCTGCCAAACACTCAGGTCTG-3 with an expected fragment length of $110 \mathrm{bp}$. The primers of the second round were forward: 5'-CTGGATCATTTTCCGATG-3' and reverse: 5'-TGATACCACTTATCGCACTT-3' with an expected fragment length of $350 \mathrm{bp}$. The PCR conditions in the first and second round were as previously mentioned $^{[6]}$.

DNA Sequencing and Sequence Alignment: Twelve PCR products form the second round nestedPCR were sent abroad (Macrogen/Korea) for direct sequencing. The resultant sequences were aligned with 24 references sequences in the National Center for Biotechnology Information (NCBI) using Basic local alignment search tool (BLAST). The identitity between the local and reference sequences was calculated. Mega 6 software was used to construct the phylogenetic tree for L. torpica and L. major local isolates.

\section{Results}

Gel Electrophoresis: The nested PCR products of the first and second round were subjected to a $2 \%$ agarose gel electrophoresis and examined by exposure to ultra violate lightafter Red Stain staining (Figure 1).

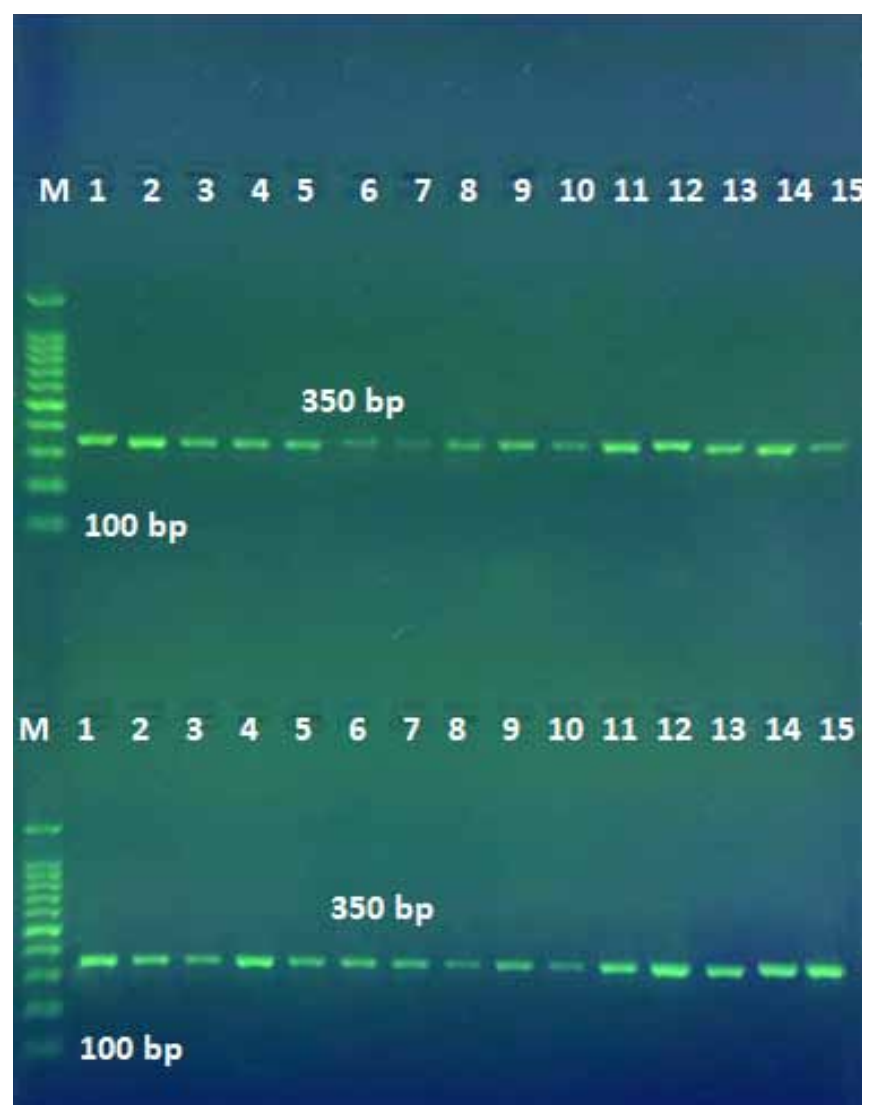

Figure 1: Gel electrophoresis on 2\% agarose at 5 volt $/ \mathrm{cm}^{2}$ of first (upper) and second (lower) nested PCR products. M: DNA ladder, lanes 1-15: PCR products from CL patients 
Sequencing and Sequence Alignment: The PCR products of 12 samples were sent abroad to Macrogen Company (Korea) for direct sequencing. The resultant sequences were compared with reference sequences using Basic Local Alignment Search Tool (BLAST) program at the National Center Biotechnology Information (NCBI) which is available online at (http:// www.ncbi.nlm.nih.gov).

According to alignment results out of 12 sequences, 9 sequences were belonging to $L$. major, while 3 sequences were belonging to $L$. tropica. All local $L$. major isolates were very close to reference isolate KP773404.1 (Iranian isolate), while all local L. tropica isolates were very close to reference isolate KY612611.1 with an identity of $98 \%$.

The base substitution, location of this substitution, nucleotide change each isolates in relation to reference isolates are presented in table 1 . The base substitution ranged from 2-6 bases at different sites of the gene with identities ranging from $97-99 \%$.

Table 1: The base substitution, location of this substitution, nucleotide change for each isolate in relation to reference isolates

\begin{tabular}{|c|c|c|c|c|c|}
\hline Sample number & Type of substitution & Location & Nucleotide & Sequence ID & Source \\
\hline \multirow{4}{*}{1} & Transition & 218 & $\mathrm{G}>\mathrm{A}$ & \multirow{4}{*}{ ID: KP773410.1 } & \multirow{4}{*}{ Leishmania major } \\
\hline & Transition & 224 & $A>G$ & & \\
\hline & Transvertion & 233 & $\mathrm{C}>\mathrm{A}$ & & \\
\hline & Transition & 268 & $\mathrm{~T}>\mathrm{C}$ & & \\
\hline \multirow{3}{*}{2} & Transition & 218 & $\mathrm{G}>\mathrm{A}$ & \multirow{3}{*}{ ID: KP773410.1 } & \multirow{3}{*}{ Leishmania major } \\
\hline & Transition & 224 & $A>G$ & & \\
\hline & Transvertion & 233 & $\mathrm{C}>\mathrm{A}$ & & \\
\hline \multirow{5}{*}{3} & Transition & 164 & $\mathrm{~A}>\mathrm{G}$ & \multirow{5}{*}{ ID: KP773410.1 } & \multirow{5}{*}{ Leishmania major } \\
\hline & Transition & 218 & $\mathrm{G}>\mathrm{A}$ & & \\
\hline & Transition & 224 & $\mathrm{~A}>\mathrm{G}$ & & \\
\hline & Transvertion & 233 & $\mathrm{C}>\mathrm{A}$ & & \\
\hline & Transition & 268 & $\mathrm{~T}>\mathrm{C}$ & & \\
\hline \multirow{5}{*}{4} & Transition & 112 & $\mathrm{~T}>\mathrm{C}$ & \multirow{5}{*}{ ID: KP773410.1 } & \multirow{5}{*}{ Leishmania major } \\
\hline & Transvertion & 180 & $\mathrm{G}>\mathrm{C}$ & & \\
\hline & Transition & 218 & $\mathrm{G}>\mathrm{A}$ & & \\
\hline & Transition & 224 & $\mathrm{~A}>\mathrm{G}$ & & \\
\hline & Transvertion & 233 & $\mathrm{C}>\mathrm{A}$ & & \\
\hline \multirow{6}{*}{5} & Transition & 145 & $A>G$ & \multirow{6}{*}{ ID: KP773410.1 } & \multirow{6}{*}{ Leishmania major } \\
\hline & Transvertion & 208 & $\mathrm{G}>\mathrm{C}$ & & \\
\hline & Transition & 218 & $\mathrm{G}>\mathrm{A}$ & & \\
\hline & Transition & 224 & $\mathrm{~A}>\mathrm{G}$ & & \\
\hline & Transvertion & 233 & $\mathrm{C}>\mathrm{A}$ & & \\
\hline & Transition & 268 & $\mathrm{~T}>\mathrm{C}$ & & \\
\hline
\end{tabular}




\begin{tabular}{|c|c|c|c|c|c|}
\hline Sample number & Type of substitution & Location & Nucleotide & Sequence ID & Source \\
\hline \multirow{6}{*}{6} & Transition & 218 & $\mathrm{G}>\mathrm{A}$ & \multirow{6}{*}{ ID: KP773410.1 } & \multirow{6}{*}{ Leishmania major } \\
\hline & Transition & 224 & $\mathrm{~A}>\mathrm{G}$ & & \\
\hline & Transvertion & 233 & $\mathrm{C}>\mathrm{A}$ & & \\
\hline & Transition & 269 & $\mathrm{~T}>\mathrm{C}$ & & \\
\hline & Transvertion & 297 & $\mathrm{~A}>\mathrm{T}$ & & \\
\hline & Transvertion & 299 & $\mathrm{~T}>\mathrm{G}$ & & \\
\hline \multirow{5}{*}{7} & Transition & 178 & $\mathrm{~T}>\mathrm{C}$ & \multirow{5}{*}{ ID: KY612611.1 } & \multirow{5}{*}{ Leishmania tropica } \\
\hline & Transition & 179 & $\mathrm{G}>\mathrm{A}$ & & \\
\hline & Transition & 185 & $\mathrm{~A}>\mathrm{G}$ & & \\
\hline & Transvertion & 194 & $\mathrm{C}>\mathrm{A}$ & & \\
\hline & Transition & 229 & $\mathrm{~T}>\mathrm{C}$ & & \\
\hline \multirow{5}{*}{8} & Transition & 178 & $\mathrm{~T}>\mathrm{C}$ & \multirow{5}{*}{ ID: KY612611.1 } & \multirow{5}{*}{ Leishmania tropica } \\
\hline & Transition & 179 & $\mathrm{G}>\mathrm{A}$ & & \\
\hline & Transition & 185 & $\mathrm{~A}>\mathrm{G}$ & & \\
\hline & Transvertion & 194 & $\mathrm{C}>\mathrm{A}$ & & \\
\hline & Transition & 229 & $\mathrm{~T}>\mathrm{C}$ & & \\
\hline \multirow{6}{*}{9} & Transition & 139 & $A>G$ & \multirow{6}{*}{ ID: KY612611.1 } & \multirow{6}{*}{ Leishmania tropica } \\
\hline & Transition & 178 & $\mathrm{~T}>\mathrm{C}$ & & \\
\hline & Transition & 179 & $\mathrm{G}>\mathrm{A}$ & & \\
\hline & Transition & 185 & $A>G$ & & \\
\hline & Transvertion & 194 & $\mathrm{C}>\mathrm{A}$ & & \\
\hline & Transition & 199 & $\mathrm{C}>\mathrm{T}$ & & \\
\hline \multirow{3}{*}{10} & Transition & 168 & $\mathrm{G}>\mathrm{A}$ & \multirow{3}{*}{ ID: KP773410.1 } & \multirow{3}{*}{ Leishmania major } \\
\hline & Transvertion & 233 & $\mathrm{C}>\mathrm{A}$ & & \\
\hline & Transition & 268 & $\mathrm{~T}>\mathrm{C}$ & & \\
\hline \multirow{2}{*}{11} & Transition & 268 & $\mathrm{~T}>\mathrm{C}$ & \multirow{2}{*}{ ID: KP773410.1 } & \multirow{2}{*}{ Leishmania major } \\
\hline & Transition & 293 & $\mathrm{G}>\mathrm{A}$ & & \\
\hline \multirow{7}{*}{12} & Transition & 46 & $\mathrm{G}>\mathrm{A}$ & \multirow{7}{*}{ ID: KP773410.1 } & \multirow{7}{*}{ Leishmania major } \\
\hline & Transition & 218 & $\mathrm{G}>\mathrm{A}$ & & \\
\hline & Transition & 224 & $\mathrm{~A}>\mathrm{G}$ & & \\
\hline & Transvertion & 233 & $\mathrm{C}>\mathrm{A}$ & & \\
\hline & Transition & 268 & $\mathrm{~T}>\mathrm{C}$ & & \\
\hline & Transition & 295 & $\mathrm{~T}>\mathrm{C}$ & & \\
\hline & Transition & 304 & $\mathrm{~T}>\mathrm{C}$ & & \\
\hline
\end{tabular}

Phylogenetic Tree: Mega 6 software was used to construct the phylogenetic tree of the local isolate of L. tropica in relation with 14 most closest reference isolates (Figure 2). The tree showed two main clades: on containing three reference isolates (from USA, Libya and Tunisia) and the other clade involving the local isolate and all the other reference isolates. The closest isolates for local Leishmania was the Iranian isolate. 


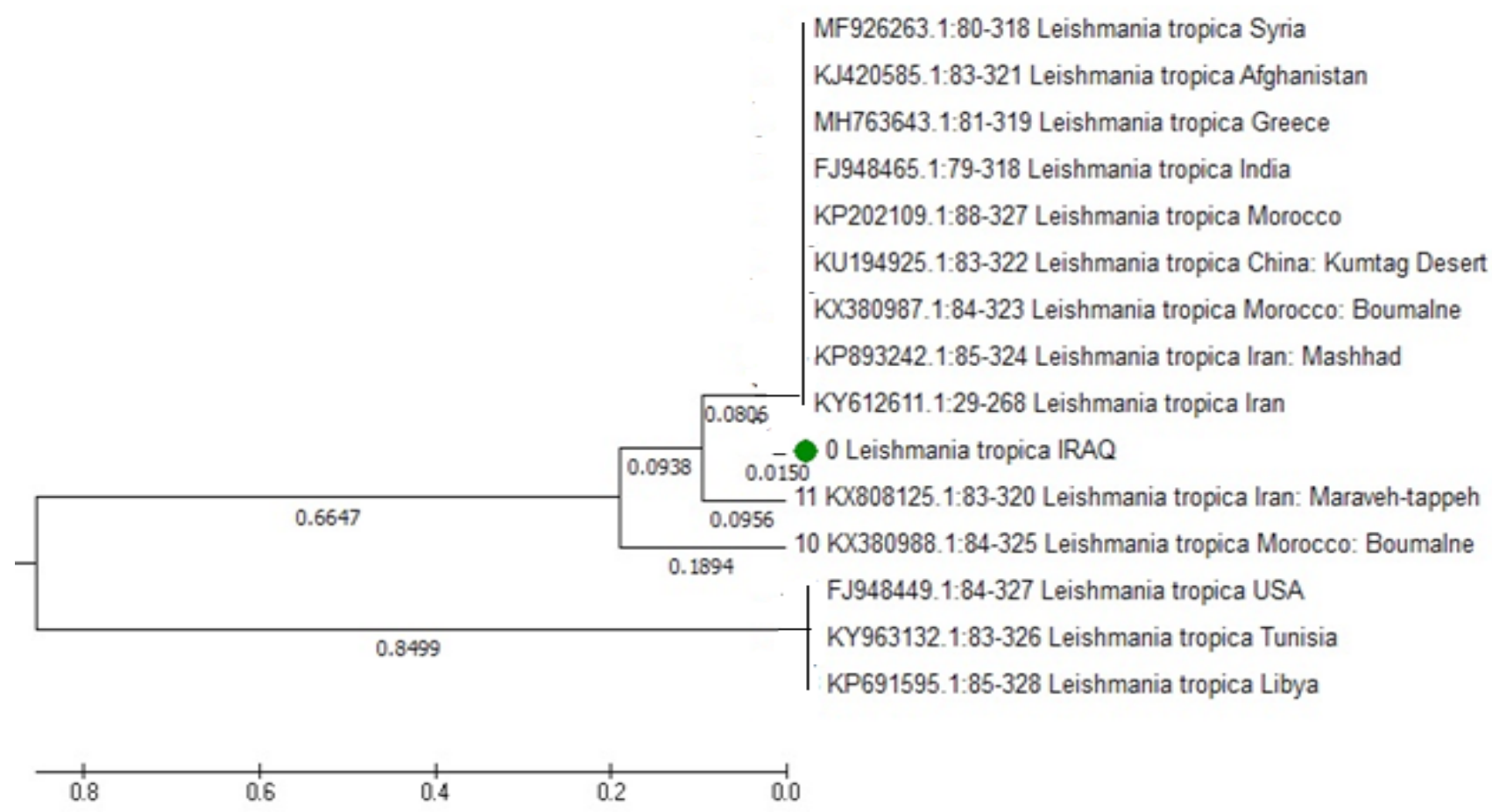

Figure 2: Phylogenetic trees for 5.8S rRNA gene constructed by the maximum likelihood method for local L. tropica isolate and 14 reference isolates. Phylogenetic distance was estimated using the Kimura twoparameter model. The tree was supported by bootstrapping with 1000 replicates $^{[7]}$.

Similarly, a phylogenetic tree was constructed between the local isolate of $L$. major with 14 closest reference isolates. The tree (Figure 3) had two main clades: one contains only a Turkish isolate while the

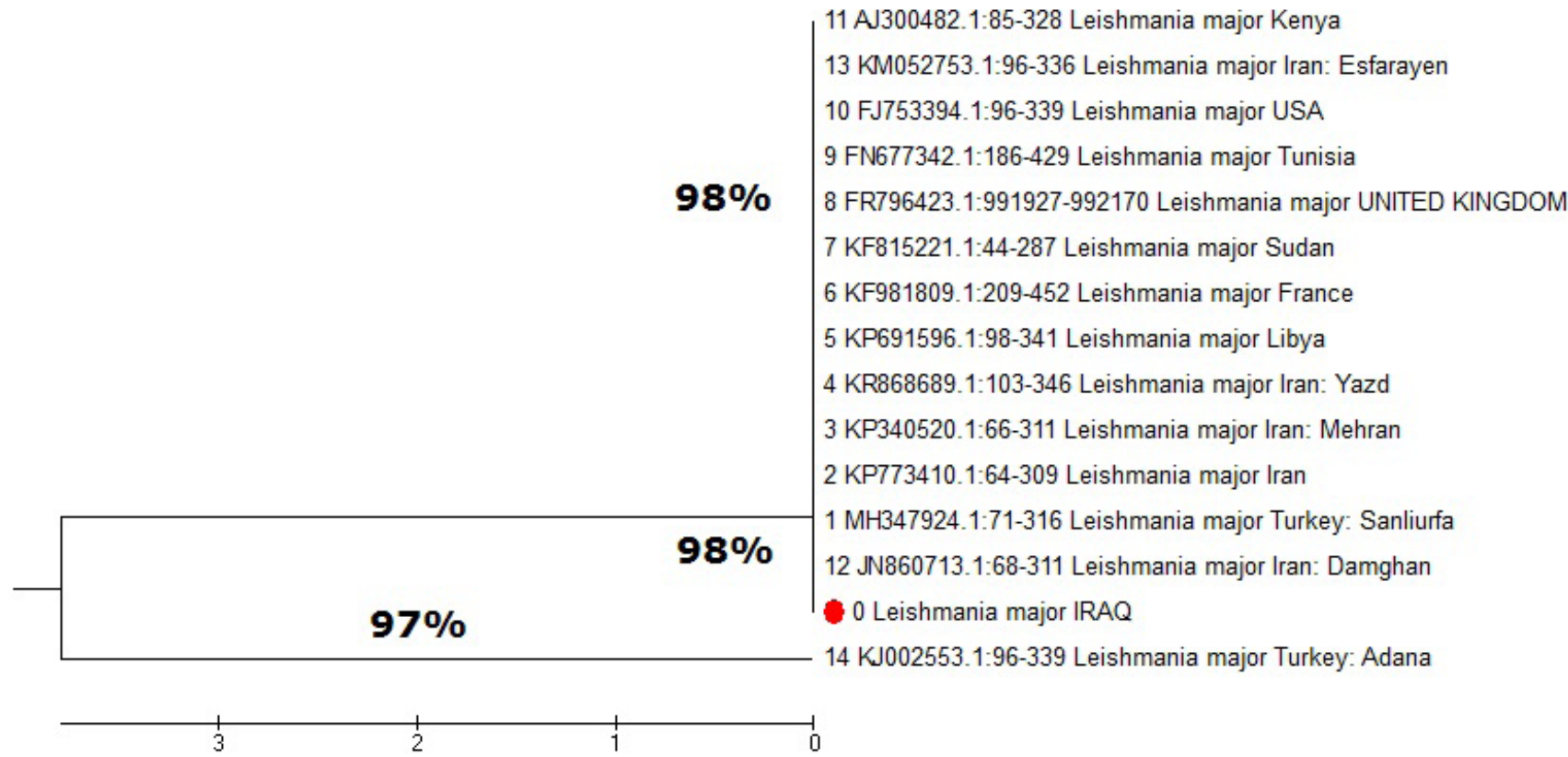

Figure 3: Phylogenetic trees for 5.8S rRNA gene constructed by the maximum likelihood method for local L. major isolate and 14 reference isolates. Phylogenetic distance was estimated using the Kimura twoparameter model. The tree was supported by bootstrapping with 1000 replicates $^{[7]}$. 


\section{Discussion}

To evaluate genetic diversity of Leishmania, authors have employed several DNA markers whether nuclear or extranuclear. The most commonly used markers wer 18S-rRNA, mini-exon, gp63 gene locus, HSP-70, microsatellites, minicircles of kinetoplast DNA (kDNA), ribosomal internal transcribed spacer regions (ITS-rDNA) and cytochrome b (Cyt b) (kDNA maxicircle) $[8,9]$. The ITS-rDNA marker, for example, was utilized to deduce the evolutionary relationships in genus Leishmania because of its conserved region with relatively low intracellular polymorphisms ${ }^{[10]}$.

The most interesting finding in the current study was that the limited variation among the investigated isolates compared with the other international studies. For example, in Iran, Mohammadihaet al. ${ }^{[11]}$ amplifies the ITS-rDNA gene for 25 isolates and used RFLP for genotyping of PCR products. The authors reported high diversity among isolates whether they belong to L. tropica or L. major. In another study, Azmi et al. ${ }^{[12]}$ reported that L. tropica is a very heterogenous species and this was evidenced by low bootstrap values obtained on the phylogenetic tree. The low diversity in the current study may be attributed mainly to a geographical reason, because almost all samples were collected from a small geographical location.

The other most interesting finding was that local isolated had a relatively high compatibility to isolates from different countries. In fact, this does not reflect a reciprocal transmission from these countries to Iraq and vice versa. Rather, in such countries, different isolates have been recorded in NCBI, among which there are some isolates which resemble other international isolates including Iraqi isolates.

Collectively, these data indicate that local isolates of CL (whether L. major of L. tropica) have less genetic variability compared with internal isolates and they are very close to their counterpart Iranian isolates. As such, it is of paramount importance to restrict the individual travelling between the two countries for effective control of the diseases especially for anthropotic CL.

Acknowledgement: The authors highly appreciate the great help from Dr. Mohammed Ali during the blood sample collection

Conflict of Interest: The authors declare that they have no conflict of interest.
Ethical Clearance: This study was approved by the Institutional Review Board/College of Medicine/Diayla University. A consent from each patient was obtained prior to data collection after explaining the aim of study. The confidentiality of data throughout the study was guaranteed and the included patients were assured that data will be used for research purpose only.

Funding: Self-funding

\section{References}

1. GBD DALYs and HALE Collaborators. Global, regional and national disability-adjusted life-years (DALYs) for 315 diseases and injuries and healthy life expectancy (HALE), 1990-2015: a systematic analysis for the Global Burden of Disease Study 2015. Lancet 2015;388:1603-58.

2. Bailey F, Mondragon-Shem K, Hotez P, RuizPostigo J, Al-Salem W, Acosta-Serrano A, et al. . A new perspective on cutaneous leishmaniasis - Implications for global prevalence and burden of disease estimates. PLoSNegl Trop Dis. 2017;11(8):e0005739.

3. Alvar J, Velez ID, Bern C, Herrero M, Desjeux $\mathrm{M}$, Cano J, et al. Leishmaniasis worldwide and global estimates of its incidence. PLoS One. 2012;7(5):e35671.

4. El-Beshbishy HA, Al-Ali KH, El-Badry AA. Molecular characterization of cutaneous leishmaniasis in Al-Madinah Al-Munawarah province, western Saudi Arabia. Int J Infect Dis 2013;17(5):e334-e338.

5. Fakhar M, Ghohe HP, Rasooli SA, Karamian M, Mohib AS, Hezarjaribi HZ, et al. Genetic diversity of Leishmania tropica strains isolated from clinical forms of cutaneous leishmaniasis in rural districts of Herat province, Western Afghanistan, based on ITS1-rDNA. Infect Genet Evolution 2016;41:120127.

6. Salloum T, Khalifeh I, Tokajian S. Detection, molecular typing and phylogenetic analysis of Leishmania isolated from cases of leishmaniasis among Syrian refugees in Lebanon. Parasite Epidemiol Control 2016;1(2):159-168.

7. Tamura K, Peterson D, Peterson N, Stecher G, Nei G, Kumar S. MEGA5: Molecular evolutionary genetics analysis using maximum likelihood, evolutionary distance and maximum parsimony method. Mol Biol Evol 2011; 28:2731-2739. 
8. Montalvo-Alvarez AM, Nodarse JF, Goodridge IM, Fidalgo LM, Marin M, Van Der Auwera G, et al. Differentiation of Leishmania (Viannia) panamensis and Leishmania (V.) guyanensis using Bcc I for hsp 70 PCR-RFLP. Trans Royal Society Trop Med Hyg 2010;104(5):364-367.

9. Bordbar A, Parvizi P. High infection frequency, low diversity of Leishmania major and first detection of Leishmania turanica in human in northern Iran. Acta Tropica2014;133:69-72.

10. Parvizi P, Moradi G, Akbari G, Farahmand M, Ready PD, Piazak N, et al. PCR detection and sequencing of parasite ITS-rDNA gene from reservoirs host of zoonotic cutaneous leishmaniasis in central Iran. Parasitol Res 2008;103(6), 1273.
11. Mohammadiha A, Dalimi A, Mohebali M, Sharifi I, Mahmoudi M, Mirzaei A, et al. Molecular identification and phylogenetic classification of Leishmania spp. isolated from human cutaneous leishmaniasis in Iran: A cross-sectional study. Iranian J Parasitol 2018;13(3):351.

12. Azmi K, Nasereddin A, Ereqat S, Schnur L, Schonian G, Abdeen Z. Method incorporating a polymerase chain reaction and restriction fragment length polymorphism and their use as a 'gold standard'in diagnosing Old World cutaneous leishmaniasis. Diag Microbiol Infect Dis 2011;71(2): 151-155. 